CASE 5.-Mitral regurgitation, with dropsy-Venous pulsation and murmur-Good effects of elaterium, \&c.

A woman, aged thirty-eight, came under my care at the South Dispensary, on the 16 th of January, 1845. She states that she has had cough and shortness of breath for nine weeks, and that three days ago her face and legs began to be much swelled. In May last she had an attack of acute rheumatism, which confined her to bed for a week, and she did not completely recover for two months. Ever since, though she had no pain at the heart during the attack, she has been rather short of breath, and has had some palpitation, which has been felt chiefly in the epigastrium, and at the lower part of the sternum. She has had unpleasant dreams, and has twice started up in a state of great oppression. Never expectorated any blood; the pulse is 70 , rather weak and small, impulse slightly increased; the first sound is heard over the lower part of the sternum, and is accompanied by a bellows-murmur, which is most distinct at the apex and towards the left side, but is also audible at the lower part of the sternum and slightly at the base of the heart; there is a very evident pulsation in the veins of the neck on both sides; the pulsation is double; the first precedes the palse at the wrist, the second bears to the first a relation which may be compared to that between the first and second sounds of the heart. On applying the stethoscope over the internal jugular vein, two very peculiar sounds are heard, which seem to be caused by the interruption, at each pulsation, of a venous murmur, which would otherwise be continuous, for on pressing the vein higher up with the finger, the sounds are entirely prevented.

Diagnosis.-Insufficiener of the mitral and tricuspid ralres. Slight hypertrophy, with dilatation.-D Elaterium, one sixth of a grain; chloride of mercury, two grains; bitartrate of potass, one drachm; compound jalap powder, two scruples. Make a powder, to be taken once or twice a day. - $\mathrm{h}$ Compound camphor tincture, two ounces; oxymel of squills, two ounces ; tincture of digitalis, two drachms. A teaspoonful of the mixture to be taken when the cough is troublesome.

19th. - She has expectorated about a cupful of blood, which seemed to relieve her breathing. The powders have purged her freely, and the swelling of the legs is a little diminished. Pulse 70 . To continue the same medicines.

23rd. - The powders have purged her very freely, and have also caused sickness and vomiting. She has, however, been much benefited. Some swelling which she had in the abdomen has dis appeared; the palpitation is lessened; and the cough bas nearly left her. To continue the powders, and the mixture for the cough occasionally.- $\mathrm{R}$ Tincture of digitalis, two drachms; spirit of nitric ether, one ounce; iodide of potassium, one drachm; decoc tion of broom-tops, eleven ounces. Two tablespoonfuls of this mixture to be taken three times a day.

30th. - She is now much better. The swelling has entirely left every part except below the knees, where there is still some œdema. The mixture has acted well as a diuretic, and only one powder has been taken. The apperite has become good. The venous pulsations are about 67 in the half minute, the pulse at the wrist being 70 in the minute. The same medicines to be continued.

Feb. 10th.-She is very well, and has come to show herself. There is scarcely any cough, and no cedema remaining. The impulse of the heart is diminished, and the murmur at the apex is less distinct. The pulsation in the veins continues. Pulse 62.

Very recently, I had an opportunity of seeing her again, and she stated that her health had continued good, that she had no cough, and no palpitation unless she exerted herself much. The murmur, with the first sound at the apex, was still very distinct when the action of the heart was excited, but became much less so after she had been a few minutes at rest. The pulsation in the veins was still visible, but had dımınished very considerably, and there was no venous murmur.

The rheumatic attack, which here laid the foundation of ralvular affection of the heart, caused the disease in the most insidious manner, and it shows, therefore, the importance of examining the heart with the stethoscope in all cases of acute rheumatism. The existence of a bellows-murmur in the first sound, with its maximum of intensity at the apex, indicated mitral regurgitation; and it is probable, from the strength of the impulse, and the loudness of the first sound at the lower part of the sternum, that this had produced dilatation and hypertrophy of the cavities of the right side of the heart. The insufficiency of the tricuspid valve, indicated by the jugular pulsation, may have been occasioned by such dilatation, or it may have been caused, in common with the mitral affection, by the rheumatic inflammation. The interruption of the venous murmur by the reflux of the blood in the veins, is worthy of notice. It is the first case in which I have ob. served this.
The case further shows the beneficial effects which, in many instances, result from elaterium in combination with other hydrogogue cathartics, and with diureties, and their power in thus, for a time, at least, removing the symptoms of the disease. It is probable, however, that this patient will be subject to winter cough, and that, if severe, a return of dropsical effusion will occur.

June, 1845

\section{MICROSCOPIC AND CHEMICAI EXAMINATION OF MENSTRUAL FLUID WHICH HAD BEEN RETAINED FOR SOME TIME WITHIN THE VAGINA.}

By H. LETHEBY, Esq. M.B., Lecturer on Chemistry at the London Hospital.

But few examinations have been made of the menstrual fluid, either in health or disease, so that we know little or nothing of its chemical composition. I have therefore taken advantage of an opportunity afforded by the following case of retention in order to seek a little farther into its history.

S. S-, a girl of weak and delicate frame, aged seventeen, had been suffering for more than a month past from a violent bearing-down pain, which extended from the loins to the inside of the thighs. She said that she had never menstruated, though she had suffered something like this upon several n_evious occasions, but that she always got better, and did not consult anybody for it. She complained, also, of a swelling within the genitals, and upon making an examination, it was found that the menses were retained by a hymen, which extended obliquely across the vagina. The membrane was exceedingly tense, and bulged out, from the pressure of the enclosed fluid; when cut into, it permitted the escape of about forty ounces of a thick and almost black fluid, upon which her sufferings were instantly relieved.

The fluid was preserved for examination; it had a dark-chocolate colour, becoming red on exposure to the air; it was perfectly inodorous, and so tenacious, that it could scarcely be poured from the vessel; altogether it had the appearance of a dark and thick treacle. Its specific gravity was 1027, a little lower than ordinary serum.

When examined under the microscope, with a power of 300 , it was found to be quice free from fibrin, or rather from that form of it which occurs in the coagnlum of blood-but consisted of numerons corpuscles floating in a coloured fluid. These corpuscles differed very considerably in form, size, and colour, so that, for description, it becomes necessary to arrange them as follows :-

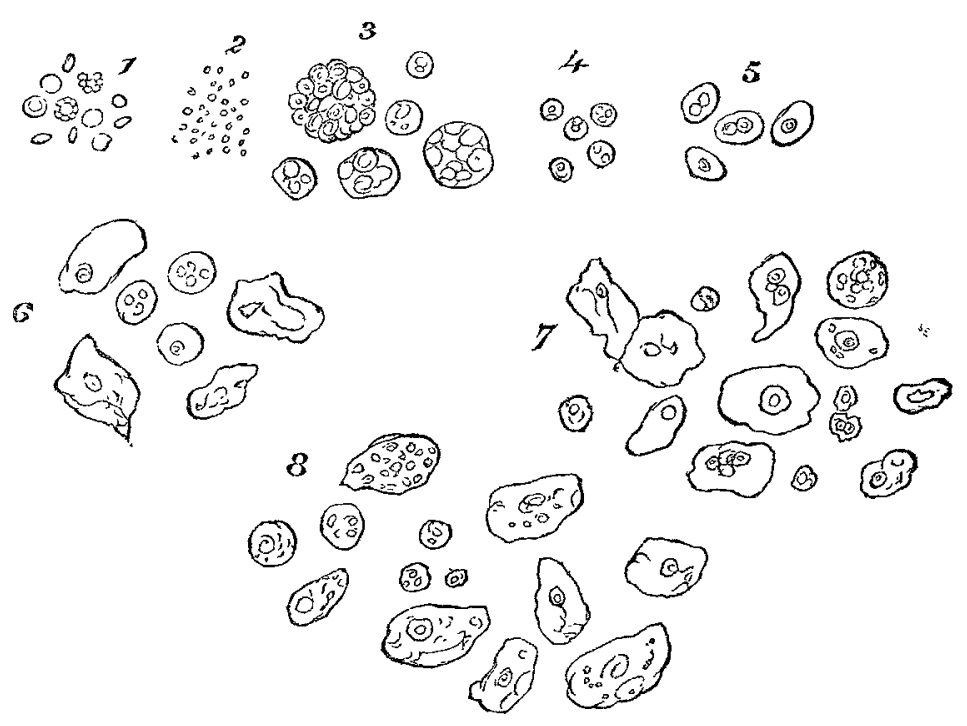

EXPLANATION OF FIGURES.

Corpuscles \&c. in menstrual fiuid, exanined with a power of 300 .

1. Altered blocd corpuscles, appearing oval when sem edgeways.

2. Minute granules, probably trom ruptured blood corpuscles.

3. Coherent blood corpuscles or exudation globules.

4. Highly refractive globules, indistinctly nucleated, (lymph globule ?)

4. Highly refractive globules, indistinctly
5. Oval corpuscles, mono or bi nucleated.

6. Epithelium scales and mucous globules.

7. Globules and epithelium remaininz atter the action of acetic acid, the nuclei more distinct.

8. Coloured exudation, mucous, and Jymph globules, with piaster epithelium, left after the action of water.

1st. By far the greater number consisted of altered blood discs, which had become so tumid from distention, that when they were viewed edgeways they appeared doubly convex, or oval, (fig. 1.) They measured from the $\frac{1}{450}$ th to the $\frac{1}{30}$ th of an inch in diameter, and some of them had acquired that peculiar beaded ap- 
pearance which the blood corpuscle occasionally assumes after exposure to the air.

2ndly. There was a multitude of very minute grannles, (fig. 2, ) looking like mere dots ; the largest did not exceed the $\frac{1}{20000}{ }^{\text {th }}$ of an inch in diameter; they appeared like the small granules which are sometimes emitted from the blood corpuscle, and I am inclined to believe that this might have been their origin.

3rdly. Some large coloured globules, densely nucleated, (fig. 3,) which at first appeared like adherent blood discs, but a further examination showed that they were the exudation globule of Gerber, the granule cell of Vogel, or the inflammatory globule of Gluge and others. They varied in size from the $\frac{1}{800}$ th to the ${ }^{2}$ th of an inch in diameter, and contained two or more nuclei.

4thly. There were many colourless cells (lymph globules) appearing indistinctly nucleated, (fig. 4 ;) these were highly refractive, and were made more distinct when the focal distance was increased; they measured about the $\frac{1}{2000^{t h}}$ of an inch in diameter.

5thly. A few red oval corpuscles, like the blood disc of the bird, (fig. 5 ;) they were well defined, and mono or bi-nucleated; the measurement of their long diameters was about the $\frac{1}{1600}$ th of an inch, and of their short, the $\frac{1}{200}$ th of an inch.

6thly. There was a large quantity of mucous globules, which were colourless, and about three or four times the size of the blood dises, (fig. 6. )

7thly. The field also presented a great number of the scales of plaster epithelium, (fig. 6.)

With the view of testing the nature of these globules, they were subjected to the action of water, ether, and acetic acid.

Water rapidly dissolved the blood corpuscles, while the other globules and scales were either not affected, or but slightly, even after a long interval, (fig. 8.) On moving the glasses, it was observed that the solution of the blood dises had produced a tenacious kind of jelly, which bound the other globules together.

Ether also dissolved the blood dises as well as the exudation globules and minute granules. The others were unaffected.

Acetic acid rapidly acted on the blood corpuscles, more slowly on the exudation globules; the others it made more distinct, bringing out their nuclei, (fig. 7.)

Chemical examination of the fluid.-It had an alkaline reaction, and was perfectly miscible with water; when heated a little below $212^{\circ}$ Fahrenheit, it formed a firm coagulum.

With the view of ascertaining the amount of its proximate principles, it was analyzed after the manner proposed by Simon.

A thousand grains of the fluid were evaporated; they gave a residue of 142.6 grains, this, when incinerated in a platinum capsule, left an ash of eight grains, of which four were peroxide of irn, the rest was soluble in water, and consisted of carbonate, muriate, phosphate, and sulphate of soda and magnesia.

A thousand grains were evaporated to dryness, over a water-bath, the residue boiled with alcohol, and then diluted with ether. By this means all the fatty matters were removed, and on evaporating the ethereo-alcoholic solution, a soapy compound was obtained, which had the peculiar odour of pastry ; it was mixed with a little wate slightly acidulated with hydrochloric acid, then filtered, and treated with ether; by which means 5.3 grains of a yellow semifluid fat was procured, and from its fluidity and capability of being saponified, it may be regarded as oleic acid mixed with a little stearic.

The residue of this operation was then boiled with dilute alcohol (specific gravity .930) and filtered while hot. The filtered solution deposited, as it cooled, 52 grains of hæmato-globulin this was collected on a filter and washed with alcohol slightly acidulated with sulphuric acid, until all the red hæmatin was dissolved through; the residual globulin weighed 49.1 grains, and the hæmatin, when precipitated by ammonia and dried, weighed three grains, .1 of which was, in all probability, sulphate of ammonia.

The alcoholic solution, from which the hæmato-globulin had been separated, yielded on evaporation 13 grains of a brown matter, composed of 6.3 grains of salts or ash, and 6.7 grains of extractive. (The previous incineration indicated 8 grains of salts, so that 1.7 grs. must have been lost during the process, or else it was in combination with the fats as soap.)

The albumen which remained after the extraction of the hæmato-globulin, salts, and fats, weighed 69.4 grains ; so that the results of these analyses might be arranged as follow:-

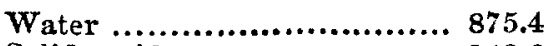

Solid residue $\ldots \ldots \ldots \ldots \ldots \ldots \ldots \ldots . . . \ldots 142.6$

1000.0

\section{Or thus -}

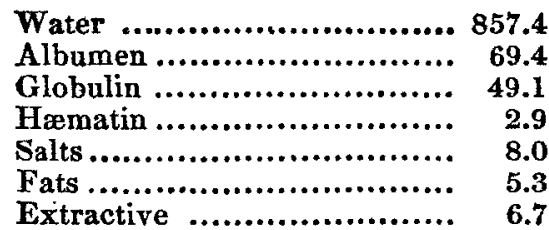

Another analysis was performed, with the view of estimating the quantity of mucus, blood corpuscles, and soluble albumen; and $I$ adopted the following process, as being more simple than any which has been hitherto suggested:-

Five hundred grains of the fluid were mixed with about eight ounces of water, and, when all the insoluble portions had subsided, it was decanted, and again treated with water, until the latter came off free from colour or albumen. The insoluble matters had still a dark-red colour, and when examined by the microscope, were found to consist of mucous, lymph, and exudation globules with epithelium, (fig. 8 ;) when dried, they weighed 11.3 grains.

The washings yielded a residue of 60.1 grains, which on ineineration left 3.5 grains of ash.

Five hundred grains of the fluid were mixed with four ounces of a solution of sulphate of soda, (sp. gr. 1020,) and allowed to stand until all the globules and corpuseles had subsided; these, when collected on a filter and dried, weighed 38.2 grs., and as by the previous experiment they must have contained 11.3 grs. of mucous and other globules, the rest-namely, 26.9-must have been blood corpuscles.

The supernatant liquor which held the soluble albumen in solution was mixed with alcohol and boiled, by which means the albumen was coagulated, and when washed and dried, it weighed 26.1 grains; so that by these analyses we may arrange its components as follow:-

Water

Solid matters insoluble in cold water, and consisting of mucous, lymph, and exudation globules with epithelium

Solid matters soluble in cold water, and consisting of, Saponified fats, and blood corpuscles ................... Albumen 857.4

Salts .........

52.7
7

These may be taken as the constituents of the fluid. It must, however, be remembered, that it can scarcely be regarded as the normal menstrual secretion; for it had been retained for a considerable time within the vagina, and no doubt it had there become mixed with various mucous secretions, as well as with an excess of the exudation globule, which its presence, as an irritant, must have occasioned. As to the cause of its viscidity, this must be looked for either in some physical property possessed by the globules, or else in the chemical action of the salts or free alkali on the albumen; for the latter has the property of giving albumen a gelatinous character. One thing is certain, it could not depend on the amount of solid matters which it contained, nor yet upon the presence of coagulated fibrin. Another property which the fluid possessed, and one which has been generally noticed, was, that it had not begun to decompose, for it had no odour, and, indeed, it appeared to resist putrefaction, after its removal from the body, longer than ordinary blood.

Now, in comparing the preceding analyses with those of normal blood, as well as of the menstrual fluid, which have been made at various times by Simon, Berzelius, Lecanu, Denis, and others, it appears that there are many points of dissimilarity; indeed, it does not bear any relation at all to healthy blood, as may be seen by the following, which is an average of two analyses made by Simon:-

\begin{tabular}{|c|c|}
\hline Water .......... & 795.278 \\
\hline Solid residue $\ldots . . . . . . . .$. & 204.822 \\
\hline Fibrin ......... & 2.104 \\
\hline Fat ... & 2.346 \\
\hline Albumen..$\ldots \ldots \ldots \ldots \ldots \ldots \ldots \ldots \ldots$ & 76.600 \\
\hline Globulin .......................... & 103.022 \\
\hline Hren & 6.209 \\
\hline ctive and salts $\ldots . . . . . .$. & 12.012 \\
\hline
\end{tabular}

From this it differs in having no fibrin, but about twice as much fat, and only half the amount of hæmato-globulin, blood corpuscles. The only form of healthy blood with which it can be compared is that of the vena porta, which Simon has found to contain more fat, but considerably less of all the albuminous principles than the systemic blood of the same animal; and there are some cases of disease, such as hæmorrhage and malcena, with which it is also comparable.

With respect to its comparison with the analyses of menstrual blood hitherto made, it offers considerable points of difference. Simon examined the menstrual fluid, and found it composed of, 


\begin{tabular}{|c|c|}
\hline Sos & \\
\hline constituents & \\
\hline & $\mathbf{2 . 5 8 0}$ \\
\hline Albumen...$\ldots \ldots \ldots \ldots \ldots \ldots$ & 76.540 \\
\hline Hæmato-globulin $\ldots \ldots \ldots \ldots \ldots$ & 120.400 \\
\hline Extractive and salts $\ldots . \ldots . \ldots . .$. & 8.600 \\
\hline
\end{tabular}

Here the solid constituents were greater than in normal blood. From an analysis of menstrual fluid made by Denis, it is composed of.

\begin{tabular}{|c|c|}
\hline 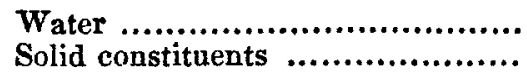 & $\begin{array}{l}825.0 \\
175.0\end{array}$ \\
\hline Fibrin....$\ldots \ldots \ldots \ldots \ldots \ldots \ldots \ldots$ & 0.5 \\
\hline Phosphorized fat .. & 3.9 \\
\hline Albumen ............. & 48.3 \\
\hline Blood corpuscles.... & 63.4 \\
\hline Mucus ............. & 45.3 \\
\hline Osmazome and cruorin ........ & 1.1 \\
\hline Soluble salts & 9.5 \\
\hline Earthy phosphates & 2.5 \\
\hline Peroxide of iron.... & 0.5 \\
\hline
\end{tabular}

And Rindskopf and Vogel's analyses, though not complete, are also closely allied to Denis's - that is, they indicate about 17 per cent. of solid residue.

Simon believes that fibrin is always present in menstrual blood, but that the mucus deprives it of the power of coagulating. I am inclined to think that his explanation is erroneous, and that the fibrin, if it exist at all in the fluid, is employed in the production of the exudation globule, for this appears to me to be the general product of that substance when blood is poured out upon any living surface.

Tredegar-square, July, 1845.

\section{ON THE USE OF ERGOT OF RYE IN PURPURA} HEMORRHAGICA AND SOME OTHER DISEASES.

By A. Ross, M.D., M.R.C.S.E, Boulogne-sur-mer, late Physician to the Suffolk General Hospital

I HAVE read with much interest, in the last number of THE LANCET, (July 19,) the case of purpura so carefully reported by $\mathrm{Mr}$. Hogg. I am not, however, quite clear as to the share of merit due to the lead in effecting the cure; nay, it appears to me, that though one of the symptoms-viz., the petechiz, began to disappear on the day on which the lead was discontinued, after three days' use, many of the most serious symptoms-the hæmorrhage from different parts of the mucous membrane, and the great constitutional disturbance, assumed a more aggravated degree after this period of the disease, and only yielded by slow steps to the various means so judiciously employed.

The report of the case extends from the 21st of April to the 25 th of May; the lead was used from the 24th till the 27 th of April; and on the 4th of May the prognosis was, as apyears to me, still very unfavourable. I think, therefore, there is room to doubt the correctness of setting down the case as one successfully treated by lead.

Nothing can be further from my intention than to imply any doubt as to the propriety of the treatment, which must be allowed to have been most judicious, and to evince much readiness of resource in a case where the symptoms continued so urgent for so long a period. My only object is to avail myself of this oppor tunity of pointing out to the profession a remedy which $I$ have found to be most energetic in a case similar to the one reported by Mr. Hogg, and which was doubtless a most obstinate one

I was asked, in the spring of 1840 , by $\mathrm{Mr}$. Stutter, at that period the zealous house-surgeon of the Suffolk General Hospital, to see, as a matter of curiosity, a young man who had just been admitted under the care of my colleague, Dr. Jackson. I forget whether Dr. Jackson had then seen him or prescribed for him but finding him labouring under purpura, with hæmorrhage from different organs, accompanied with such prostration as led us to fear that a fatal termination to the disease was not distant, I suggested, provided Dr. Jackson should approve of it, the trial of the ergot of rye, which it struck me might be usefully combined with compound infusion of roses. The use of this combination was immediate!y commenced, and continued for some days, in the dose, as far as I remember, of five grains of the powdered ergot, and an ounce of the compound infusion of roses, every four hours, with a generous diet. Under this treatment, with the addition of some aperient when necessary, the case went on with great rapidity to a favourable termination, without a single untoward symptom occurring to interrupt its progress.

The effects of the treatment were so decidedly beneficial in this case, apparently so unfavourable, that Mr. Stutter was anxious, $I$ remember, that it should be communicated at the time. to The Lancet. - However, I considered then that it might be considered premature, and am only now induced to make the communication, from my attention having been recalled to the subject by Mr. Hogg's severe case.

Several years' experience of the effects of the ergot in certain stages of labour, leaves no doubt in my mind of the value of this medicine in obstetric practice.

I have also found it a valuable remedy, combined or not with infusion of roses, in menorrhagia, and in controlling sanguineous discharge from the uterus after abortion.

I have no doubt, if my idea of the value of the ergot as a remedy in purpura should be confirmed by further trial, that it might be found useful also in sea scurvy, and other passive hæmorrhages, depending on a peculiar and vitiated state of the blood.

Boulogne, July 21st, 1845 .

\section{A NEW HAMORRHOID NEEDLE.}

By G. Borrase Chunds, Esq. Surgeon to the City Police Force.

I BEg leave to forward to you a drawing of an instrument which I have recently invented, for the purpose of applying ligatures to small tumours of the vagina and of the rectum.

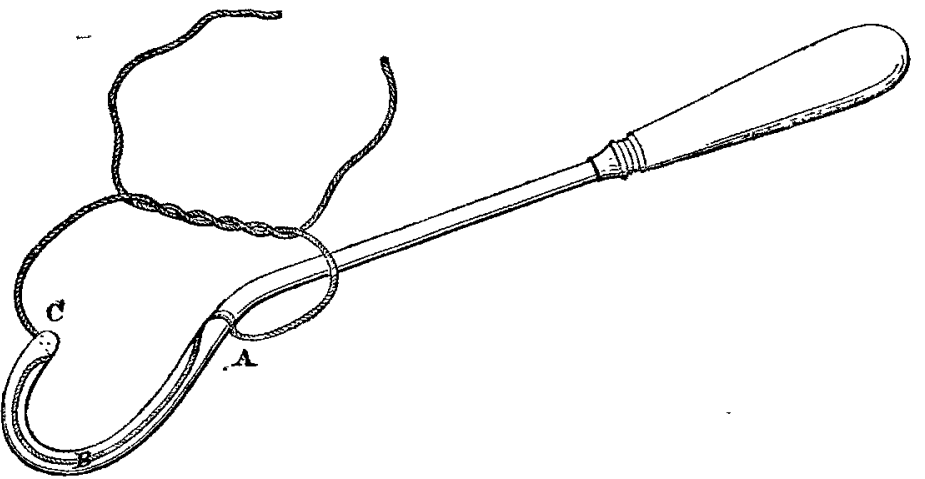

This instrument will be found particularly adapted for the removal of hæmorrhoids. It not unfrequently happens in those affections, that considerable difficulty is experienced in getting the ligature to remain close aronnd the base of the tumour, and sundry attempts are made ere the operator succeeds. This is peculiarly the case when the tumours are not very prominent their bases broad, and a number of them situated close to each other.

The ordinary mode of proceeding in such cases, is to pass the ligature around the tumour, with the right and left index fingers, either aided by a tenaculum or not, as the operator may deem expedient. With the utmost precaution, it sometimes occurs, that our endeavours to complete the operation are embarrassed by the constant slipping of the ligature, or, what is still worse, the operation may prove unsuccessful from the ligature embracing a portion only of the hamorrhoid.

Such accidents are less likely to occur when the hremorrhoid needle is resorted to, for it enables the operator, with great facility, to keep the silk in close contact with the base of the tumour, and when two or three are close together, and are situated high up the rectum, the ligature is readily passed between them.

As seen by the drawing, the instrument is of rery simple construction, and in shape is somewhat similar to a button-hook; on its under surface, $B$, is a groove, for the reception of the silk, which latter must be well waxed before it is used; at each extremity $c, A$, is a slit, or notch, for the purpose of nipping the silk, and retaining it in its proper situation.

The operator carries the needle, previously threaded, bebind the tumour, and with the handle slightly raised, in order that the groove may be brought to bear immediately upon its base ; he gives it to an assistant to hold, directing him to keep a steady and firm pressure downwards and outwards; the operation is then completed in the ordinary way, the ligature, as it is tied, releasing itself from the groove of the needle.

A modification of the same instrument might, I think, be advantageously resorted to for the removal of polypi, and other tumours of the uterus.*

- The needle is made by Mr. Ferguson, of West Smithfield.

Vaidy, in his article "Hygiene Militaire," in the " Dictionnaire des Sciences Medicales," states that, under the most favourable circumstances, an army will furnish about 5 per cent. of sick. During a campaign, not less than 10 per cent. must be calculated on, and in the event of reverses or other untoward circumstances, this becomes immensely increased. 